\title{
Carbon Waste Powder Prepared from Carbon Rod Waste of Zinc-Carbon Batteries for Methyl Orange Adsorption
}

\author{
Fitria Rahmawati ${ }^{1 *}$, Viona Natalia ${ }^{1}$, Agung T. Wijayanta ${ }^{2}$, Koji Nakabayashi $^{3}$, \\ Jin Miyawaki ${ }^{3}$, Siti Rondiyah ${ }^{1}$
}

\begin{abstract}
${ }^{1}$ Research Group of Solid State Chemistry and Catalysis, Chemistry Department, Sebelas Maret University, Jl. Ir. Sutami 36 A, Kentingan Surakarta, Indonesia

${ }^{2}$ Research Group of Sustainable Thermofluids, Mechanical Engineering, Sebelas Maret University, Jl. Ir. Sutami 36 A, Kentingan, Surakarta, Indonesia

${ }^{3}$ Department of Advanced Device Materials, Institute for Materials Chemistry and Engineering, Kyushu University, 6-1 Kasuga-koen, Kasuga-shi, Fukuoka 816-8580, Japan
\end{abstract}

Received: 17th June 2019; Revised: 1st September 2019; Accepted: 3 $3^{\text {rd }}$ September 2019; Available online: 28th February 2020; Published regularly: April 2020

\begin{abstract}
A research on the preparation of Carbon Waste Powder, CWP, was conducted and made from carbon rod waste which was extracted from used zinc-carbon batteries. This research was an effort to overcome environmental problem caused by battery waste by converting into adsorbent for methyl orange (MO) that frequently used by textile industries. The prepared powder was then analyzed to understand its characteristic peaks, crystallinity, and to compare the properties with other carbonaceous forms, i.e. a commercial Carbon Paper (CP), and a commercial meso- carbon micro-beads (MCMB). The analysis found that CWP is dominated by graphitic carbon. An adsorption experiment was then conducted to study their adsorption ability to methyl orange solution. The result found that those three carbonaceous materials have the ability to adsorb methyl orange with different activities. MCMB has the highest adsorption capacity of $0.197 \mathrm{mg}^{-1} \mathrm{~g}^{-1}$. Meanwhile, CWP and CP show adsorption capacity of 0.066 mg.g ${ }^{-1}$ and $0.062 \mathrm{mg} \cdot \mathrm{g}^{-1}$, respectively. Methyl orange adsorption on CWP and CP were under second order, which means the adsorption could be four times faster as the MO solution doubled. Moreover, the rate constant of MO adsorption on CWP is $8 \times 10^{-4} \mathrm{~min}^{-1}$, which was higher than the rate constant of MO adsorption on CP. It confirmed that the CWP can be used as a promising adsorbent for dye waste water. Copyright $\odot 2020$ BCREC Group. All rights reserved
\end{abstract}

Keywords: Adsorption; Carbon rod waste; Carbon waste powder; Methyl orange

How to Cite: Rahmawati, F., Natalia, V., Wijayanta, A.T., Nakabayashi, K., Miyawaki, J., Rondiyah, S. (2020). Carbon Waste Powder Prepared from Carbon Rod Waste of Zinc-Carbon Batteries for Methyl Orange Adsorption. Bulletin of Chemical Reaction Engineering \& Catalysis, 15(1): 66-73 (doi:10.9767/bcrec.15.1.5148.66-73)

Permalink/DOI: https://doi.org/10.9767/bcrec.15.1.5148.66-73

\section{Introduction}

Dye waste water has become an environmental problem due to the production of

* Corresponding Author.

E-mail: fitria@mipa.uns.ac.id (F. Rahmawati);

Telp: +62-271-663375, Fax: +62-271-663375 paper, textiles, gasoline, cosmetics, food industries, etc. [1]. Dye wastes are toxic, hazardous, and non-biodegradable [2], that may cause the destruction of aquatic living organisms [3]. As one of the dye compound, methyl orange (MO) is known as an azo anionic type that contains of $-\mathrm{N}=\mathrm{N}-$ chromophore group and aromatic structure $[4,5]$. The chromo- 
phore and aromatic group are difficult to undergo auto-degradation. Specific treatment is required to overcome the waste water, such as through membrane filtration method [6], chemical oxidation [7], adsorption [1], and also coagulation. Adsorption might be a good choice due to the ease of preparation and simplicity of the reactor design [8,9]. It is known that activated carbon is the most popular adsorbent for various dye waste water [10]. The performance of MO adsorption follows a pseudo second order [11]. Another carbon- based adsorbent is carbon nanotubes that also has the ability to adsorb MO molecules from its aqueous solution [3].

In another side, year by year solid waste batteries increases due to high demand on portable electronic devices. Primary battery still dominates the market, in which $80 \%$ battery selling in Europe, mostly alkaline and zinccarbon battery [12]. Around 160,000 tons of batteries enter the European Union every year [13]. Environmental Protection Agency (EPA) reveals that each year Americans purchase three billion dry cell battery to power radios, toys, cellular phones, watches, and portable power tools [14].

In order to reduce the waste impact to environment, some efforts must be done by reusing some components in battery waste, such as to reuse the carbon rod of zinc-carbon battery for photo catalyst substrate in hydrogen production [15], and also for raw material in graphene oxide synthesis [16]. This research also has used the carbon rods of zinc-carbon battery waste for preparing adsorbent powder, named as carbon waste powder, CWP. The novelty of this work is its raw material, which is unique for creating a specific adsorbent powder. The powder was then applied to adsorb methyl orange, MO, from its aqueous solution. The adsorption performance was compared to other carbonaceous forms, i.e. carbon paper, $\mathrm{CP}$, and meso-carbon micro-beads, MCMB. Adsorption equilibrium study was conducted to determine the adsorption capacity (mg.g $\left.{ }^{-1}\right)$. Kinetics of adsorption determines the adsorption rate, the rate constant, and the order of adsorption. Meanwhile, isotherm explains the adsorption type between single or multi-layer and also predicts the type of interaction between adsorbate molecules and the prepared carbon as the adsorbent. The present effort contributes to the understanding of characteristics of the proposed adsorbent derived from waste material aims to provide an environmental protection.

\section{Materials and Methods}

\subsection{Material Preparation and Characterization}

Carbon waste powder, CWP, was produced from carbon rod waste extracted from a zinccarbon battery (ABC battery, Indonesia). The carbon rods waste were cleaned by dipping in ethanol liquid and then washed with distilled water followed by drying at $105^{\circ} \mathrm{C}$ for $1 \mathrm{~h}$ [15], and then crushed into powder. The prepared powder was then analyzed by XRD (Rigaku Mini Flex 600 X-Ray diffraction instrument with $\mathrm{Cu}-\mathrm{Ka}$ radiation $(\lambda=1.5406 \AA)$ in $2 \theta$ range of $10-70^{\circ}$. A commercial MCMB powder (MTI scientific, bead size around 6-52 $\mu \mathrm{m}$ ) and a commercial carbon paper (the Fuel Cell store, cut into pieces with a size of $1 \times 1 \mathrm{~cm}^{2}$ ) were used for comparison. The MCMB and CP were also analyzed by XRD to identify the carbonaceous peaks. Scanning Electron Microscopy, SEM (FEI Inspect s50) analyzed surface morphology as well as to estimate the particle size by applying Measure IT software (a free edition). Adsorption isotherm, total pore volume $\left(\mathrm{cm}^{3} \cdot \mathrm{g}^{-1}\right)$, and surface area $\left(\mathrm{m}^{2} \cdot \mathrm{g}^{-1}\right)$ of the prepared CWP were identified by applying a BET instrument (NOVA touch $4 \mathrm{LX}$ ).

\subsection{Adsorption Experiment}

The aqueous MO stock solution was prepared by dissolving $100 \mathrm{mg}$ MO into $1000 \mathrm{~mL}$ of deionized water (Merck, Germany with molecular weight $\left.327.34 \mathrm{gmol}^{-1}\right)$. The adsorption experiment was conducted at room temperature at the various contact time, and the MO solution concentration. In order to get the maximum absorbance of $\mathrm{MO}$, a various concentration of MO solution was prepared at $0,2,4$, 6,8 , and $10 \mathrm{ppm}$, and the solution then being scanned between 100-700 nm of light wavelength in a UV-Vis spectrophotometer (Perkin Elmer Lambda 25). It is found that MO reveals a maximum absorbance at $465 \mathrm{~nm}$.

Adsorption experiment was conducted by poured a $0.5 \mathrm{~g}$ adsorbent into $50 \mathrm{~mL}$ of 100 ppm MO solution in a flacon. The mixture was then shaken for 0-300 minutes, in which, to collect data, $2 \mathrm{~mL}$ of solution was diluted to 25 $\mathrm{mL}$, which was then analyzed by UV-Vis spectrophotometer at $465 \mathrm{~nm}$. The optimum time of adsorption was determined by plotting absorbance, $A$, data to the time of adsorption, $t$ (min), and the optimum time was reached when the absorbance value starts to be constant. The optimum time was then used for the MO adsorption isotherm calculation. The MO adsorption 
isotherm was studied at $2,4,6,8$, and $10 \mathrm{ppm}$ of MO solution adsorbed onto $0.5 \mathrm{~g}$ adsorbent. The initial rate, or the rate of adsorption before reaching equilibrium was used for kinetics study of each adsorption process. Data of MO adsorbed onto the absorbents, $C_{a d s}\left(\mathrm{mg} . \mathrm{L}^{-1}\right)$, was used to understand the pattern of adsorption on each adsorbent, and confirms the suitability with kinetics study.

The adsorbed amount of MO at equilibrium, $q_{e}(\mathrm{mg} / \mathrm{g})$ was calculated by Equation (1) [17]:

$$
q_{e}=\frac{\left(C_{o}-C_{e}\right) V}{W}
$$

$C_{o}$ and $C_{e}\left(\mathrm{mg} . \mathrm{L}^{-1}\right)$ are initial and the equilibrium concentration of MO solution, respectively; $W(\mathrm{~g})$ is the weight of adsorbent used and $V(\mathrm{~L})$ is the volume of solution. Langmuir and Freundlich's isotherm was applied to analyze the adsorption data. The material

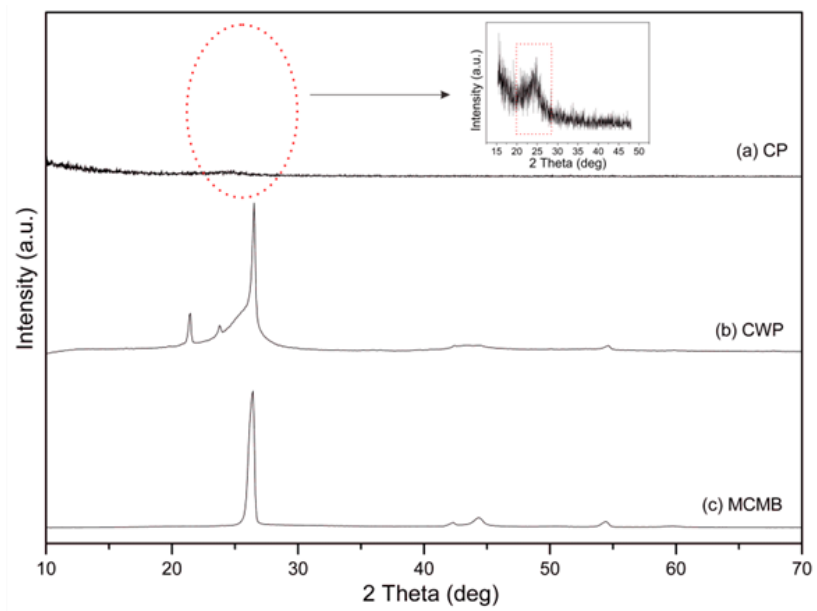

(a)

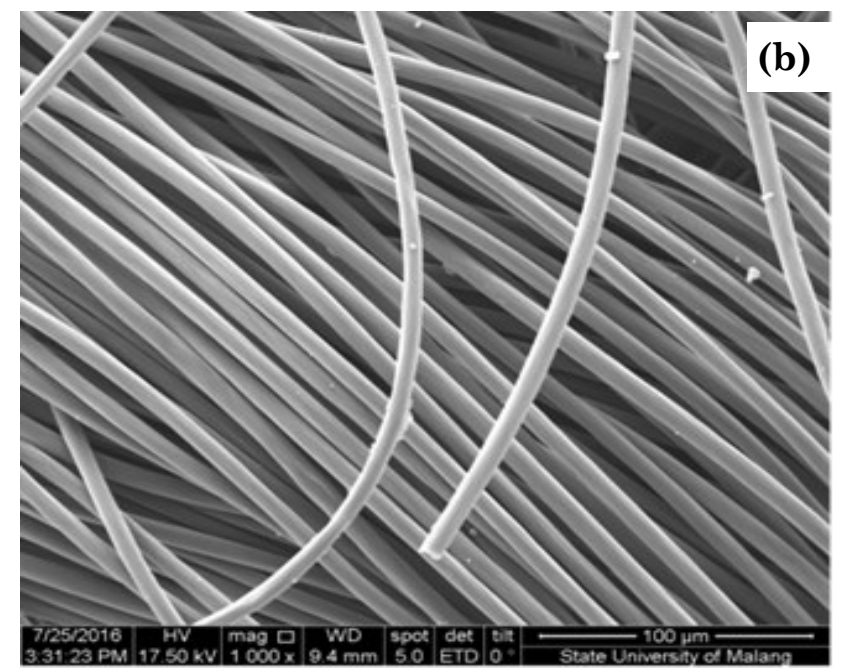

analysis was conducted by applying FTIR spectrophotometer (Shimadzu Infrared Prestige 21 with $\mathrm{KBr}$ pellet as substrate) to understand the change in their functional group at before and after adsorption.

Enthalpy of adsorption, $\Delta H_{a d s}$ was determined by plotting $\ln C_{e}$ to $1 / T\left(\mathrm{~K}^{-1}\right)$ following Clausius-Clapeyron equation (eq. 2) [18], in which $T$ is temperature (K), $R$ is gas constant $8.314 \mathrm{~J} . \mathrm{mol}^{-1} \cdot \mathrm{K}^{-1}$ and $C$ is a constant, available as intercept in the linear regression. Data for thermodynamics plot was found by conducting adsorption experiment at the time of equilibrium under room temperature $\left(28^{\circ} \mathrm{C}\right), 30,40$, and $50{ }^{\circ} \mathrm{C}$. The adsorption was conducted twice for each temperature. The result was presented as average value with standard deviation of each.

$$
\ln C_{e}=-\frac{\Delta H}{R T}+C
$$

\section{Results and Discussion}

X-ray diffraction pattern of the prepared carbon waste powder is depicted in Figure 1(a), compared to the diffraction pattern of the MCMB and CP. A broad peak lying at $2 \theta$ of $22-25^{\circ}$ appears in the CWP diffraction pattern indicates the presence of amorphous carbon as it was also found in the previous research [15]. CP diffraction pattern shows very low intensity peak at around $2 \theta$ of $24.5^{\circ}$ indicates the presence of amorphous carbon. The amorphous phase of $\mathrm{CP}$ is confirmed by the broad and noisy diffraction pattern compare to the other carbonaceous phases. Meanwhile, CWP and

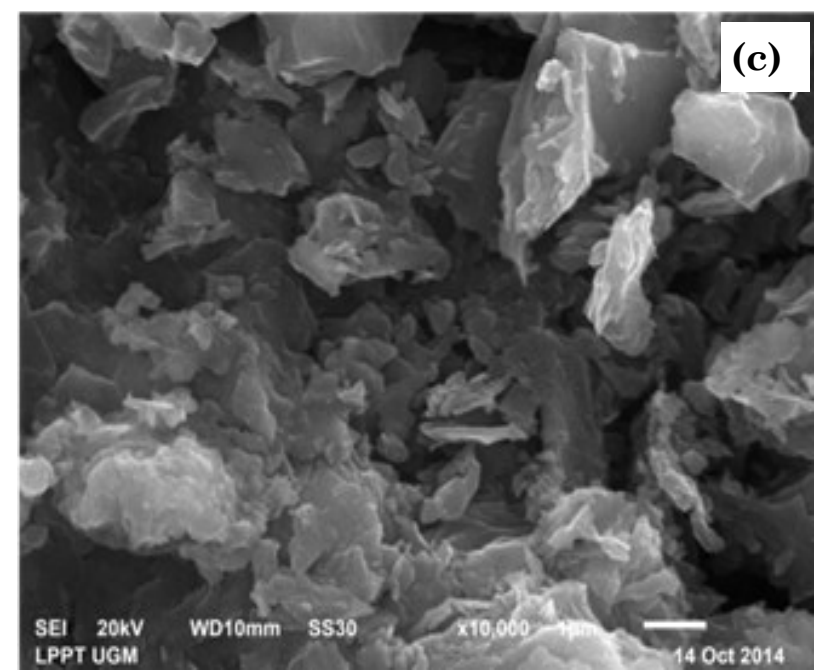

Figure 1. (a) The diffraction pattern of the carbon from carbon rod waste (CWP) in comparison with carbon paper (CP) and commercial graphite (MCMB) and (a) SEM images of carbon paper and (c) carbon waste powder. 
MCMB show a strong peak at $2 \theta$ of $26.3^{\circ}$ which is identified as graphitic carbon, as well as peaks at $2 \theta$ of $44.23^{\circ}$ and $54.61^{\circ}$. The graphitic carbon peaks are in agreement with standard graphite diffraction of ICSD\#53781.

Morphological analysis by SEM resulted in images as depicted in Figure 1(b) and (c). Carbon paper as illustrated in Figure 1(b) describes a homogenous wire with a diameter of around $5.5 \mu \mathrm{m}$. Meanwhile, carbon waste powder shows a rough and non-homogenous surface morphology as describes in Figure 1(c).

The adsorption of MO molecules by CWP is shown by the changes in the FT-IR spectra (Figure 2) at before and after adsorption. The CWP spectrum after adsorption exhibits characteristic peaks at $1552.76 \mathrm{~cm}^{-1}$ and $1083.08 \mathrm{~cm}^{-1}$, that indicate $\mathrm{N}=\mathrm{N}$ vibration from

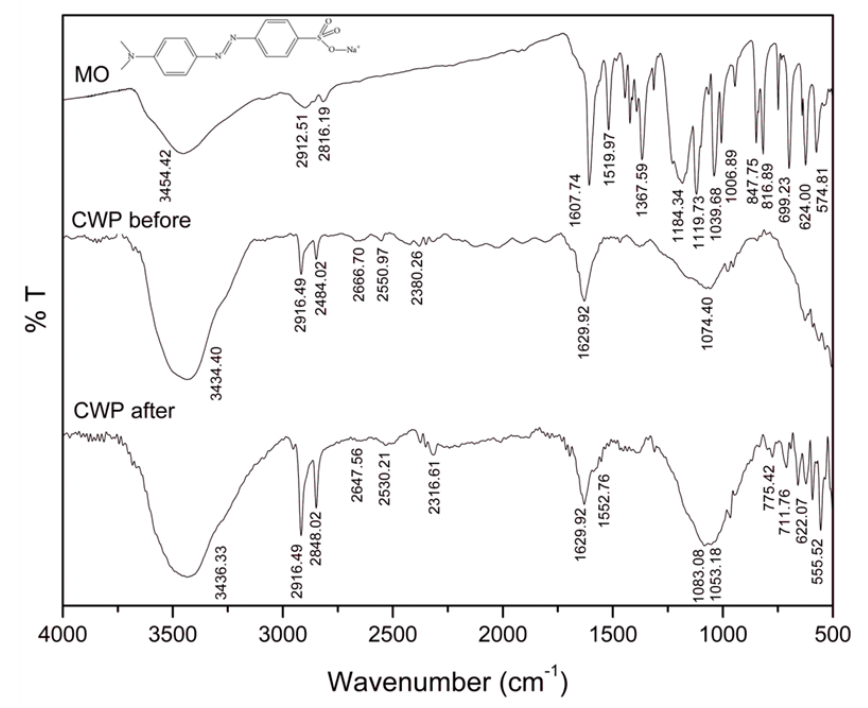

Figure 2. The characteristic pattern of FTIR spectra of the MO, CWP before adsorption and after adsorption of MO after 300 minutes with concentration $\mathrm{MO}$ of $10 \mathrm{mg} . \mathrm{L}^{-1}$.

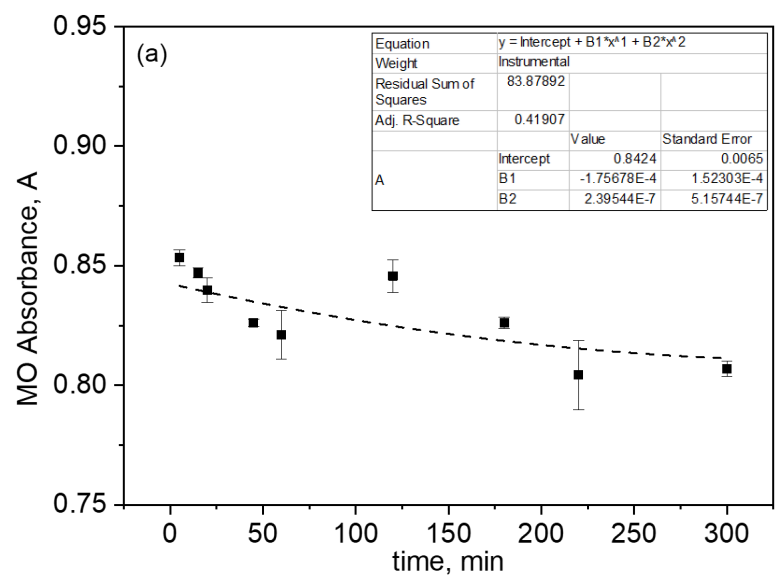

the azo bond, and $\mathrm{S}=\mathrm{O}$ vibration, respectively [19]. Meanwhile, the peaks at $1053.18 \mathrm{~cm}^{-1}$, $775.00 \mathrm{~cm}^{-1}$, and $622.07 \mathrm{~cm}^{-1}$ are attributed to $\mathrm{C}-\mathrm{H}$ stretching of aromatic rings. The peak at $555.52 \mathrm{~cm}^{-1}$ corresponds to $\mathrm{C}-\mathrm{S}$ stretching vibration [19]. All peaks are relatively weak due to low MO solution concentration, i.e. 10 mg.L $\mathrm{L}^{-1}$, allowing a limit quantity of MO molecules to be adsorbed. A peak at around 3400 $\mathrm{cm}^{-1}$ that provide in all spectrum refers to $\mathrm{O}-\mathrm{H}$ stretching of water molecules. Another peak at 2800-3000 $\mathrm{cm}^{-1}$ corresponds to the antisymmetric and symmetric stretching vibration of $-\mathrm{CH}_{3}[20]$.

Adsorption test produced a plot of absorbance, $A$ to time, $t$ (min) as depicted in Figure 3 (a). The absorbance plot confirms that the adsorption reached equilibrium after $200 \mathrm{~min}$ MO adsorption to CWP. The adsorption rate was fast at the first $50 \mathrm{~min}$ before it turned into a slow rate and then reached equilibrium. In order to compare adsorption performance between CWP, CP, and MCMB, a plot of the adsorbed amount (mg.g ${ }^{-1}$ adsorbent) versus time (min) is described in Figure 3 (b). The plot shows that MCMB provides the highest adsorption capacity value, i.e. $0.197 \mathrm{mg}^{\mathrm{g}}{ }^{-1}$. Meanwhile, the adsorption capacity of MO to

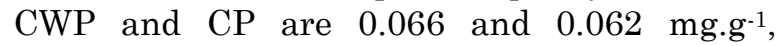
respectively.

Kinetics study was taken at before the adsorption reach equilibrium, or at initial rate adsorption. By applying first and second order rate law, it was found that adsorption of MO to CWP and CP follow second order rate law with a rate constant of $8 \times 10^{-4} \mathrm{~min}^{-1}$ and $2 \times 10^{-4} \mathrm{~min}^{-1}$, respectively. Meanwhile, MO adsorption to MCMB follows first order with a rate constant of $7 \times 10^{-4} \mathrm{~min}^{-1}$. It means that, when the MO concentration increases twice, the adsorption

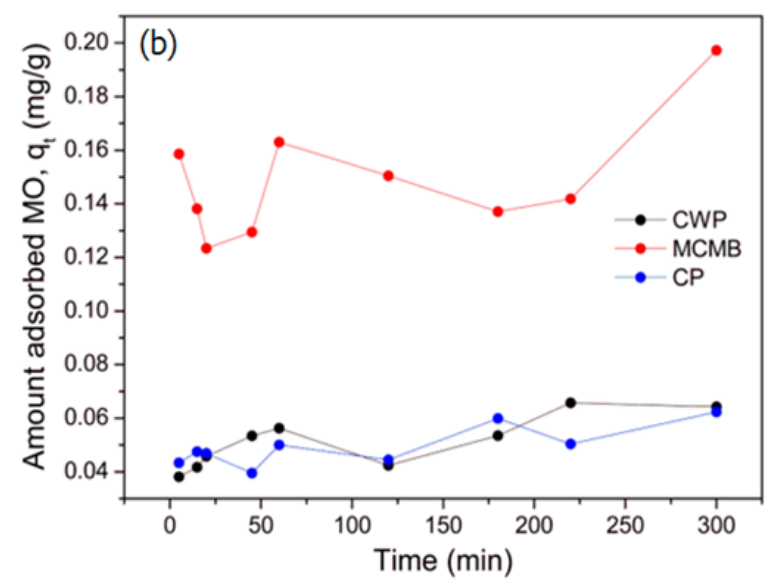

Figure 3. (a) Plot of absorbance to the time of adsorption on CWP, and (b) Plot of adsorption amount to the time of adsorption with the various adsorbent. The $\mathrm{MO}$ solution is $10 \mathrm{mg} . \mathrm{L}^{-1}$. 
on CWP and CP will be four times faster. However, the adsorption rate will increase only twice when MCMB is used as an adsorbent. It is proved by conducting adsorption at a various initial concentration of MO solution. The result can be checked in Figure 4, in which Kinetics parameters are listed in Table 1. Figure 4 shows that when the MO concentration was 2 ppm, MO adsorption onto CWP was less than the adsorption onto MCMB. However, by MO

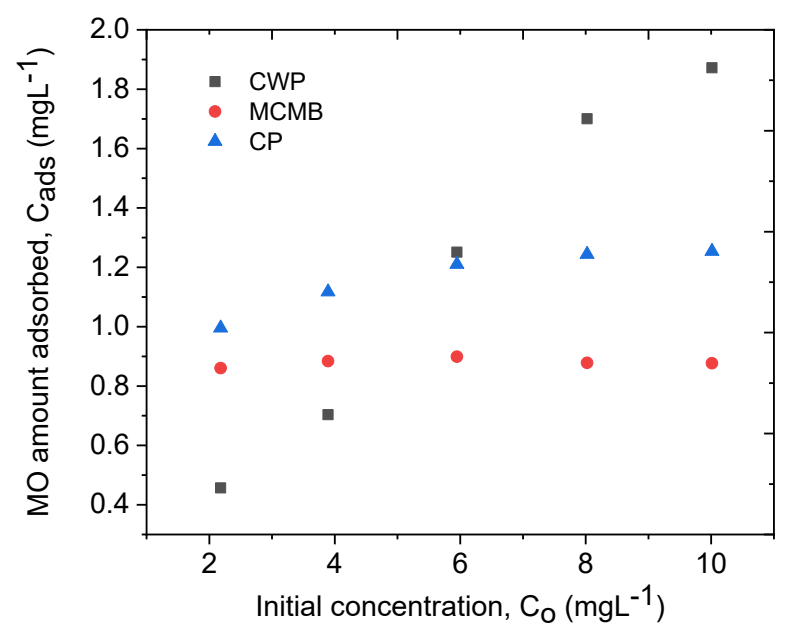

Figure 4. Plot of MO amount adsorbed, $C_{\text {ads }}$, at a various initial MO concentration, $C_{0}$

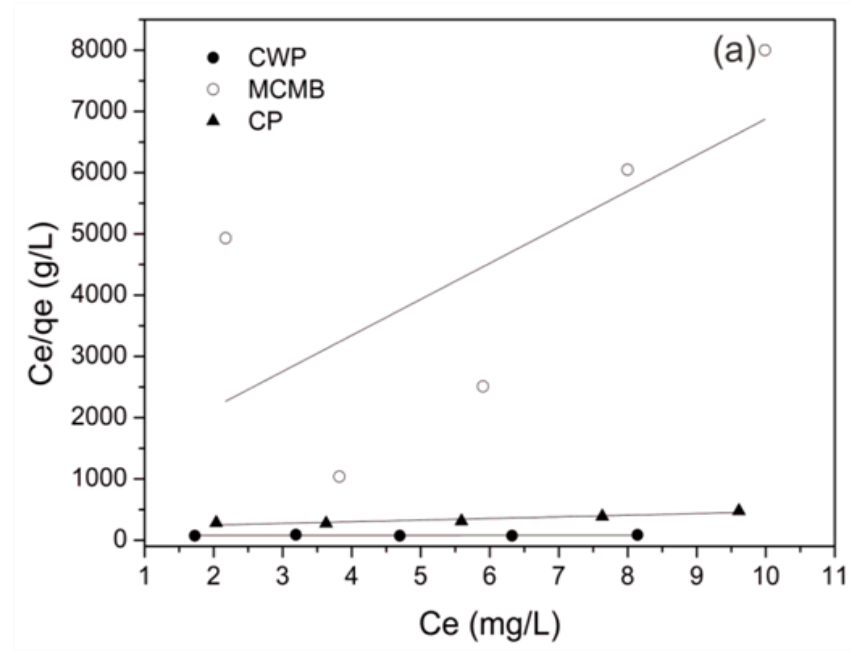

concentration increasing, the adsorption onto CWP shows a higher increment than MO onto MCBM. Meanwhile, MO adsorption onto CP has similar type with MO adsorption onto MCMB, even though kinetics study found that the MO adsorption onto CP follows second order kinetics. It indicates that high MO desorption from $\mathrm{CP}$ surface due to low interaction between the molecules with the surface, as it is confirms that the adsorption follows Freundlich isotherm (Table 2). Freundlich isotherm fits with a multilayer adsorption supported by physical adsorption.

Adsorption capacity at every contact time refers to $q_{e}$ (mg.g-1) was plotted to Langmuir and Freundlich Isotherm (Equation (3) and (4) $[17,21]$. The isotherm study how is the distribution of molecular adsorption on adsorbent when the adsorption reach equilibrium [11].

$$
\frac{C_{e}}{q_{e}}=\frac{1}{q_{m} K_{L}}+\frac{C_{e}}{q_{m}}
$$

$q_{m}$ is maximum monolayer capacity of adsorbent (mg.g $\left.\mathrm{g}^{-1}\right), \quad C_{e}$ is the equilibrium concentration of MO solution (mg.L-1) and $K_{L}$ is Langmuir adsorption constant (L.mg-1). The Langmuir adsorption isotherms describe quantitatively the formation of a monolayer adsorbate on the outer surface of the adsorbent

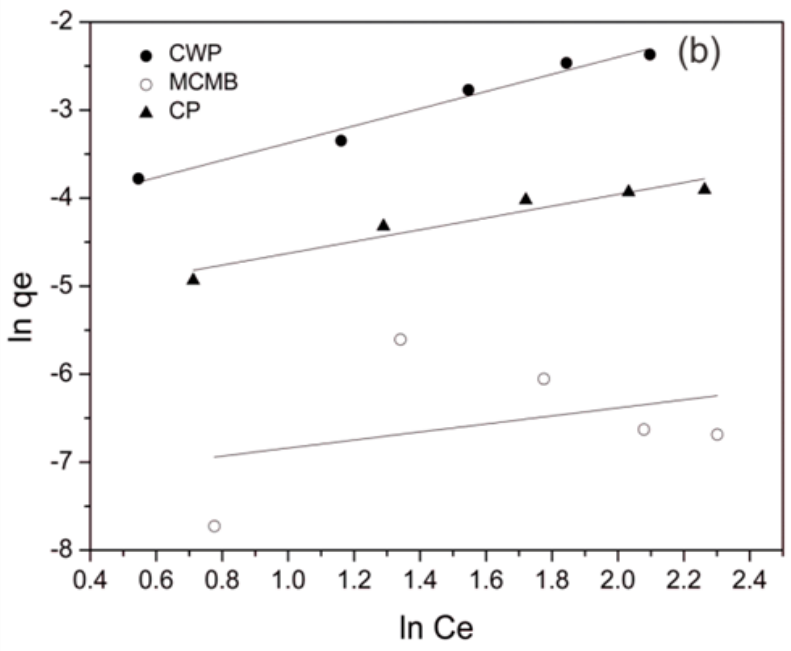

Figure 5. The linear of plot (a) Langmuir and (b) Freundlich isotherms.

Table 1. The kinetics parameters of rate constant $(k)$ and the linearity coefficient $\left(\mathrm{R}^{2}\right)$ for $\mathrm{CP}, \mathrm{CWP}$, and MCMB adsorbent.

\begin{tabular}{|c|c|c|c|c|c|}
\hline \multirow{2}{*}{ No. } & \multirow{2}{*}{ Materials } & \multicolumn{2}{|c|}{$1^{\text {st }}$ order kinetics } & \multicolumn{2}{|c|}{$2^{\text {nd }}$ order kinetics } \\
\hline & & $k_{1}$ & $\mathrm{R}^{2}$ & $k_{2}$ & $\mathrm{R}^{2}$ \\
\hline 1 & $\mathrm{CP}$ & $1 \times 10^{-4}$ & 0.5765 & $2 \times 10^{-4}$ & 0.9877 \\
\hline 2 & MCMB & $7 \times 10^{-4}$ & 0.9989 & $11 \times 10^{-4}$ & 0.9984 \\
\hline 3 & CWP & $2 \times 10^{-4}$ & 0.6394 & $8 \times 10^{-4}$ & 0.9020 \\
\hline
\end{tabular}


[22]. The values of $q_{m}$ and $K_{L}$ were calculated from the slope and intercept of the Langmuir plot of $C_{e} / q_{e}$ versus $C_{e}$ as shown by Figure 5 .

Freundlich adsorption isotherms (equation (4)) describes the heterogeneity of the adsorbent and multi-layer coverage of adsorbate [22].

$$
\ln q_{e}=\ln K_{F}+\frac{1}{n} \ln C_{e}
$$

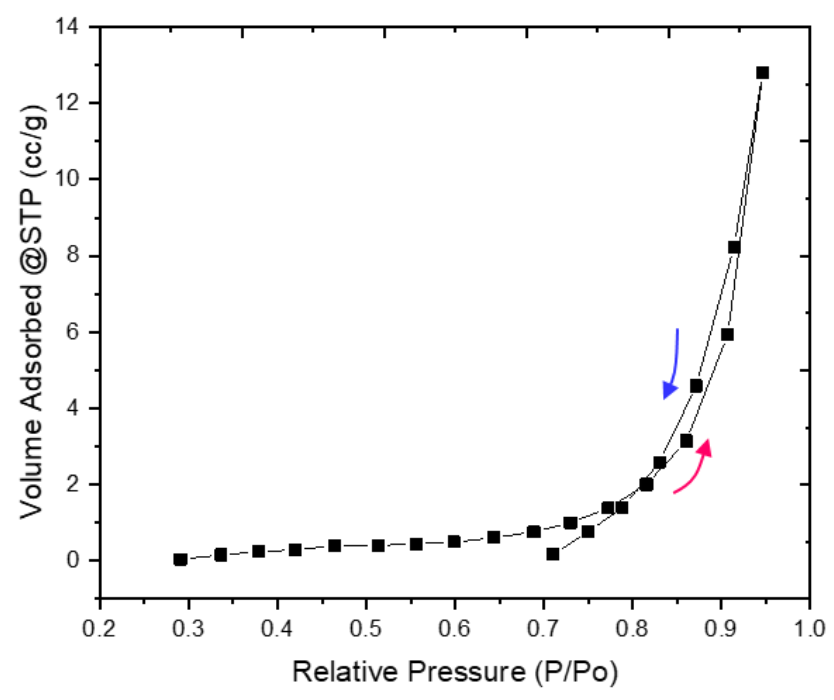

Figure 6. Adsorption isotherm profile of $\mathrm{N}_{2}$ gas adsorption to Carbon Waste Powder, CWP at 41.58 ${ }^{\circ} \mathrm{C}$ ambient temperature. Red arrow refers adsorption, and blue arrow refers desorption.

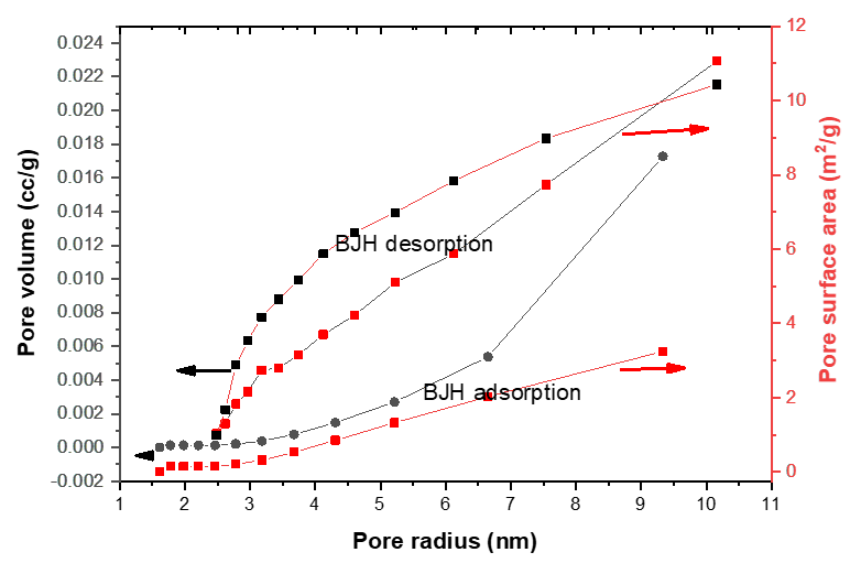

Figure 7. The adsorption and desorption BJH pore size distribution of $\mathrm{N}_{2}$ gas on CWP powder.
$K_{F}$ and $n$ are the Freundlich isotherms constant. The higher value of $K_{F}$ and $n$ are indicated higher adsorption capacity and stronger adsorption bond between adsorbate and adsorbent, respectively [17]. The values of $K_{F}$ and $n$ is calculated from the intercept and slope of the plot $\ln C_{e}$ versus $\ln q_{e}$. The linear plot of Langmuir and Freundlich are shown in Figure 5, meanwhile the isotherm parameters are listed in Table 2. The correlation coefficient $\left(\mathrm{R}^{2}\right)$ clarify the suitability of isotherm application.

The $K_{F}$ and $n$ values of MO sorption on CWP are $0.0129(\mathrm{mg} / \mathrm{g})(\mathrm{L} / \mathrm{mg})^{1 / \mathrm{n}}$ and 0.9770 , respectively. The value of $1 / n=0.9770$ as listed in Table 2 indicating the appropriate adsorption of MO. In which, the value below 1 means normal adsorption, while the $1 / n$ value above 1 indicates cooperative adsorption [22,23].

Table 2 confirms that MO adsorption on CWP and CP comply with Freundlich isotherm, with a coefficient of 0.9762 and 0.9239, respectively. Meanwhile, MO adsorption on MCMB follows Langmuir isotherm. The result indicates that MO molecules are adsorbed to MCMB as a single layer and MO molecules are adsorbed to CWP and CP as a multilayer. The results are in line with the kinetics study, in which MO adsorption on MCMB follows the $1^{\text {st }}$ order. Even though MO concentration contributes to the adsorption capacity, the contribution will not as high as adsorption on

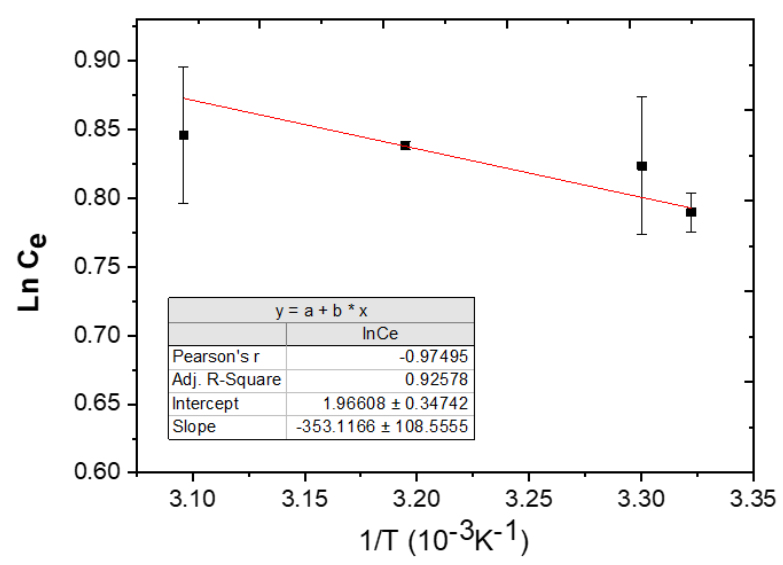

Figure 8. Clausius - Clapeyron plot for the determination of adsorption enthalpy.

Table 2. Parameters of the Langmuir and Freundlich isotherms for various adsorbent

\begin{tabular}{lccccccc}
\hline \multirow{2}{*}{ Sample } & \multicolumn{3}{c}{ Langmuir } & & \multicolumn{3}{c}{ Freundlich } \\
\cline { 2 - 4 } \cline { 6 - 8 } & $q_{m}\left(\mathrm{mg}^{-1} \mathrm{~g}^{-1}\right)$ & $K_{L}\left(\mathrm{~L} \cdot \mathrm{mg}^{-1}\right)$ & $\mathrm{R}^{2}$ & & $K_{F}\left(\mathrm{mg} \cdot \mathrm{g}^{-1}\right)\left(\mathrm{L} \cdot \mathrm{mg}^{-1}\right)^{1 / \mathrm{n}}$ & $1 / n$ & $\mathrm{R}^{2}$ \\
\hline CWP & 2.2261 & 0.0284 & 0.0216 & & 0.0129 & 0.9770 & 0.9762 \\
MCMB & 0.0017 & 0.5959 & 0.4427 & & 0.0006 & 0.4562 & 0.1212 \\
CP & 0.0374 & 0.1376 & 0.8882 & & 0.0050 & 0.6698 & 0.9239 \\
\hline
\end{tabular}


CWP and CP, which have four times higher contribution. Monolayer adsorption may have a stronger interaction between adsorbateadsorbent. However, the molecules adsorb are less quantity than multilayer adsorption.

The multilayer adsorption on CWP was further analyzed by conducting a BET isotherm analysis under $\mathrm{N}_{2}$ gas flows. The isotherm profile is described in Figure 6. It shows that the adsorption capacity reached $12.8 \mathrm{cc} . \mathrm{g}^{-1}$ when nitrogen supplied up to 0.95 of relative pressure. Completed- $\mathrm{N}_{2}$ desorption occurred when the relative partial pressure dropped close to 0.7 relative pressure. A small hysteresis loop between adsorption-desorption curve indicates a multilayer MO adsorption on the CWP surface, in which adsorbate-adsorbent interaction usually low in a multilayer term. It causes desorption to occur faster than adsorption. It may also be caused by irreversible adsorption, in which adsorption itself distord the structure of adsorbent [24]. Structure distortion of adsorbent may change pore size of adsorbent, change the surface area, as well as change adsorption capacity from monolayer to multilayer. Structure distortion may also cause the different BJH pore size distribution based on adsorption and desorption result. Both curves of results is described in Figure 7. BJH calculation resulted in the total pore volume of $1.9853 \times 10^{-2} \mathrm{~cm}^{3} \cdot \mathrm{g}^{-1}$ at relative pressure of 0.9465 , and the average pore radius is $7.229 \mathrm{~nm}$.

Thermodynamics study by plotting adsorption data to Clausius-Clapeyron equation (Figure 8), found that the adsorption occurred endothermically, with enthalpy change value,

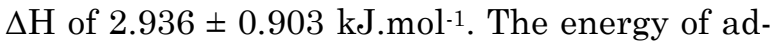
sorption is within low energy category, or the adsorption of MO on CWP powder can be claimed as physisorption. The adsorption energy less than $8 \mathrm{~kJ} . \mathrm{mol}^{-1}$ is physisorption type, in between $8-16 \mathrm{~kJ} \mathrm{~mol}^{-1}$ is ion-exchange, and over $16 \mathrm{~kJ} \mathrm{~mol}^{-1}$ is categorized as chemisorption [25].

\section{Conclusions}

Carbon Waste Powder, CWP, prepared from carbon rods extracted from zinc-carbon battery waste has the ability to adsorb methyl orange, MO, in aqueous solution. Kinetics study reveals that the MO adsorption to CWP follows second order with a rate constant of $8 \times 10^{-4} \mathrm{~min}^{-1}$. The rate constant is greater than the adsorption on carbon paper, CP, or meso-carbon micro-bead, MCMB. Even though, the adsorption capacity is $0.066 \mathrm{mg} . \mathrm{g}^{-1}$ which is lower than the adsorption capacity of MCMB to MO solution, i.e.
$0.197 \mathrm{mg} . \mathrm{g}^{-1}$. MO adsorption on CWP fits well with Freundlich isotherm, confirming multilayer coverage of MO molecules on CWP surface. The adsorption occurred through physisorption. Initial MO concentration significantly affect the adsorption rate and amount of adsorption.

\section{Acknowledgment}

This research was a part of research PNBP Sebelas Maret University, Indonesia, contract number 259/UN27/HK/2018. This research was also supported partially by a Bilateral Exchange Program JSPS/DG-RSTHE Joint Research Project 2018 grant, from the Japan Society for the Promotion of Science. Authors acknowledged these financial supports.

\section{References}

[1] Gupta, V.K., Kumar, R., Nayak, A., Saleh, T.A., Barakat, M.A. (2013). Adsorptive removal of dyes from aqueous solution onto carbon nanotubes: A review. Advance Colloid and Interface Science, 193-194, 24-34. doi:10.1016/j.cis.2013.03.003.

[2] Sharma, P., Kaur, H., Sharma, M., Sahore, V. (2011). A review on applicability of naturally available adsorbents for the removal of hazardous dyes from aqueous waste. Environmental Monitoring Assessment, 183, 151-95. doi:10.1007/s10661-011-1914-0.

[3] Zhao, D., Zhang, W., Chen, C., Wang, X. (2013). Adsorption of Methyl Orange Dye Onto Multiwalled Carbon Nanotubes. Procedia Environmental Science, 18, 890-895. doi:10.1016/j.proenv.2013.04.120.

[4] Hassanzadeh-Tabrizi, S.A., Motlagh, M.M., Salahshour, S. (2016). Synthesis of $\mathrm{ZnO} / \mathrm{CuO}$ nanocomposite immobilized on $\mathrm{Y}-\mathrm{Al}_{2} \mathrm{O}_{3}$ and application for removal of methyl orange. $A p$ plied Surface Science, 384, 237-243. doi:10.1016/j.apsusc.2016.04.165.

[5] Hosseini, S., Khan, M.A., Malekbala, M.R., Cheah, W., Choong, T.S.Y. (2011). Carbon coated monolith, a mesoporous material for the removal of methyl orange from aqueous phase: Adsorption and desorption studies. Chemical Engineering Journal, 171, 11241131. doi:10.1016/j.cej.2011.05.010.

[6] Liu, J., Xiong, J., Tian, C., Gao, B., Wang, L., Jia, X. (2018). The degradation of methyl orange and membrane fouling behavior in anaerobic baffled membrane bioreactor. Chemical Engineering Journal, 338, 719-725. doi:10.1016/j.cej.2018.01.052.

[7] Mazumder, N.A., Rano, R. (2018). Synthesis and Characterization of Fly Ash Modified 
Copper Oxide (FA/CuO) for Photocatalytic Degradation of Methyl Orange Dye. Material Today Proceeding, 5, 2281-2286. doi:10.1016/j.matpr.2017.09.230.

[8] Gautam, R.K., Mudhoo, A., Lofrano, G., Chattopadhyaya, M.C. (2014). Biomass-derived biosorbents for metal ions sequestration: Adsorbent modification and activation methods and adsorbent regeneration. Journal of Environmental Chemical Engineering, 2, 239-259. doi:10.1016/j.jece.2013.12.019.

[9] De Gisi, S., Lofrano, G., Grassi, M., Notarnicola, M. (2016). Characteristics and adsorption capacities of low-cost sorbents for wastewater treatment: A review. Sustainable Materials \& Technology, 9, 10-40. doi:10.1016/j.susmat.2016.06.002.

[10] Ramakrishna, K.R., Viraraghavan, T. (1997). Dye removal using low cost adsorbents. Water Science Technology, 36, 189-196. doi:10.1016/S0273-1223(97)00387-9.

[11] Gong, R., Ye, J., Dai, W., Yan, X., Hu, J., Hu, X. (2013). Adsorptive removal of methyl orange and methylene blue from aqueous solution with finger-citron-residue-based activated carbon. Industrial \& Engineering Chemistry Research, 52, 14297-14303. doi:10.1021/ie402138w.

[12] Lang, J., Matejka, V. (2013). Graphite / titanium dioxide composite. Nanocon, Brno, Czech Republic, EU: 2013. doi:10.1039/c3bm60192g.

[13] Anonym. (2018). Batteries \& Accumulators. http://ec.europa.eu/environment/waste/batteri es/index.htm (accessed April 8, 2018).

[14] Laughlin, R.B. (2008). Environmental Protection Agency - Battery Waste. http://large.stanford.edu/publications/coal/refe rences/epa/.

[15] Rahmawati, F., Yuliati, L., Alaih, I.S., Putri, F.R. (2017). Carbon rod of zinc-carbon primary battery waste as a substrate for CdS and TiO2 photocatalyst layer for visible light driven photocatalytic hydrogen production. Journal of Environmental Chemical Engineering, 5, 2251-2258. doi:10.1016/j.jece.2017.04.032.

[16] Rahmawati, F., Prasasti, B.L.W., Mudjijono, M. (2018). Graphene Oxide from Carbon Rod Waste. IOP Conference Series: Material Science and Engineering, 333, 012012. doi:10.1088/1757-899X/333/1/012012.

[17] Rattanapan, S., Srikram, J., Kongsune, P. (2017). Adsorption of Methyl Orange on Coffee grounds Activated Carbon. Energy Proce$d i a, \quad 138, \quad 949-954$. doi:10.1016/j.egypro.2017.10.064.
[18] Wang, T., Shen, C., Wang, N., Dai, J., Liu, Z., Fei, Z. (2019). Adsorption of 3Aminoacetanilide from aqueous solution by chemically modified hyper-crosslinked resins: Adsorption equilibrium, thermodynamics and selectivity. Colloids and Surfaces A Physicochemical and Engineering Aspect, 575, 346351. doi:10.1016/j.colsurfa.2019.05.029.

[19] Umamaheswari, C., Lakshmanan, A., Nagarajan, N.S. (2018). Green synthesis, characterization and catalytic degradation studies of gold nanoparticles against congo red and methyl orange. Journal of Photochemistry and Photobiology B Biology, 178, 33-39. doi:10.1016/j.jphotobiol.2017.10.017.

[20] Li, P., Song, Y., Wang, S., Tao, Z., Yu, S., Liu, Y. (2015). Enhanced decolorization of methyl orange using zero-valent copper nanoparticles under assistance of hydrodynamic cavitation. Ultrasonic Sonochemistry, 22, 132-138. doi:10.1016/j.ultsonch.2014.05.025.

[21] Zhai, L., Bai, Z., Zhu, Y., Wang, B., Luo, W. (2018). Fabrication of chitosan microspheres for efficient adsorption of methyl orange. Chinese Journal of Chemical Engineering, 26, 657-666. doi:10.1016/j.cjche.2017.08.015.

[22] Dada, A.O. (2012). Langmuir, Freundlich, Temkin and Dubinin-Radushkevich Isotherms Studies of Equilibrium Sorption of $\mathrm{Zn}$ ${ }^{2+}$ Unto Phosphoric Acid Modified Rice Husk. IOSR Journal of Applied Chemistry, 3, 38-45. doi:10.9790/5736-0313845.

[23] Mohan, S.V,, Karthikeyan, J. (1997). Removal of lignin and tannin colour from aqueous solution by adsorption onto activated charcoal. Environmental Pollution, 97, 183-187. doi:10.1016/S0269-7491(97)00025-0.

[24] Lapham, D.P., Lapham, J.L. (2019). Gas adsorption on commercial magnesium stearate: The origin of atypical isotherms and BET transform data. Powder Technology, 342, 676-689. doi:10.1016/j.powtec.2018.10.035.

[25] Shen, S., Guishen, L., Pan, T., He, J.Z., Guo, Z. (2011). Selective adsorption of Pt ions from chloride solutions obtained by leaching chlorinated spent automotive catalysts on ion exchange resin Diaion WA21J. Journal of Colloid and Interface Science, 364, 482-489. doi:10.1016/j.jcis.2011.08.043. 